\title{
LETRAMENTO MATEMÁTICO: um olhar a partir das competências matemáticas propostas na Base Nacional Comum Curricular do Ensino Fundamental
}

\author{
MATHEMATICAL LITERACY: a look based on the mathematical \\ competences in the National Curriculum Common Base
}

\author{
Fernando Souza de Arruda ${ }^{1}$ \\ Robson dos Santos Ferreira ${ }^{2}$ \\ Alan Gonçalves Lacerda ${ }^{3}$
}

\section{RESUMO}

\begin{abstract}
Este trabalho tem como objetivo analisar as características do Letramento Matemático contidas na Base Nacional Comum Curricular (BNCC) do Ensino Fundamental e suas relações com a perspectiva da Avaliação de Estudantes (PISA). A pesquisa é de cunho qualitativo, por ser pesquisa documental-bibliográfica. Por meio das análises dos documentos e leituras de bibliografia pertinente referente ao tema, observou-se que a BNCC, por meio de suas competências específicas de Matemática para o Ensino Fundamental, apresenta elementos que comtemplam a formação de estudantes Letrados em Matemática, tais como considerar a Matemática como fruto da construção humana, habilidades de resolução de problemas em diferentes contextos por meio das ferramentas matemáticas, dentre outras. Dessa forma, entende-se que a BNCC se constitui como um importante instrumento para a formação de alunos Letrados em Matemática por meio de um ensino mais crítico e reflexivo.
\end{abstract}

Palavras-chave: Letramento Matemático; BNCC; PISA.

1. Professor da rede Municipal de Breves-PA. E-mail: fernando.arruda@hotmail.com.

2. Professor da Faculdade de Matemática da UFPA campus do Marajó/Breves. E-mail: robsonf@ufpa.br.

3. Professor da Faculdade de Matemática da UFPA campus do Marajó/Breves. E-mail: alanlacerda@ufpa.br. 


\section{ABSTRACT}

This study aims to analyze the characteristics of Mathematical Literacy contained in the Common National Curriculum Base (PNCC) of Elementary School and its relations with the perspective of Student Assessment (PISA). The research is of a qualitative nature, as it is a documental-bibliographical research. Through the analysis of documents and relevant bibliographical readings related to this topic, we observed that the BNCC, through its Mathematics specific skills to Elementary School presents elements which contemplate the formation of literate students in Mathematics, such as considering Mathematics as the result of human construction, problem solving skills in different contexts through mathematical tools, among others. Thus, we understand that the BNCC constitutes itself as an important tool for the formation of Math Literate students through more critical and reflexive teaching.

Keywords: Mathematical Literacy; BNCC; PISA.

\section{Introdução}

Dentre as discussões atuais no âmbito da Educação Matemática, o processo de implementação da Base Nacional Comum Curricular (BNCC) tem ganhado destaque por orientar o planejamento de políticas de formação de professores e atualização de currículos como mencionado por diversos autores na literatura (CZIGEL e PAVANELO, 2016; BRASIL, 2017; SILVA, 2019).

A BNCC, para Czigel e Pavanelo (2019), não é algo novo, uma vez que a sua criação já estava prevista desde a Constituição de 1988, perpassando pela Lei de Diretrizes e Bases da Educação Brasileira de 1996 (LDB 9394/96), sendo que sua concepção foi ampliada no Plano Nacional da Educação (PNE) conforme a Lei no 13.005/2014 para o Ensino Médio, que trata dos direitos, conhecimentos, competências, bem como dos objetivos de aprendizagem de todos os estudantes do Brasil pertencentes à Educação Básica.

Por ser um documento recém-finalizado, ainda é fruto de muitas divergências, uma vez que, ora objetiva garantir um conjunto mínimo de competências necessárias para o aluno da Educação Básica e, ora discute-se a intencionalidade das competências apresentadas para a formação cidadã. 
No caso particular da Matemática para o Ensino Fundamental, o foco de nossa discussão busca uma perspectiva que transcenda as tradicionais técnicas de cálculo, propondo que o aluno possa desenvolver no Ensino Fundamental a competência de resolver e formular problemas, aproximando-a das ideias do Letramento Matemático, que na perspectiva apresentada pelo Programa Internacional de Avaliação de Estudantes (PISA) caracteriza-se como "a capacidade individual de formular, empregar e interpretar a matemática em uma variedade de contextos" (OECD, 2012).

A exemplo do que entendem Aguiar e Ortigão (2012), as concepções de Letramento Matemático do PISA assumem um o papel social da Educação Matemática, como a de responsabilidade em estabelecer o elo entre os conteúdos escolares e o cotidiano do aluno.

Nesse contexto, procedemos ao seguinte inquérito: Quais são as convergências existentes entre o Letramento Matemático na perspectiva do PISA e as habilidades da área da Matemática previstas na BNCC do Ensino Fundamental?

Sendo assim, buscaremos uma solução compatível com os pressupostos do Letramento Matemático contidos na BNCC. Na maioria das vezes, essas proposições refletem a criticidade e a necessidade do desenvolvimento de habilidades e competências para lidar com os desafios presentes no cotidiano escolar.

\section{Visões do Letramento Matemático para o PISA e a BNCC}

Nas últimas duas décadas no Brasil as discussões em relação aos conceitos inerentes ao Letramento Matemático têm se aprofundado, uma vez que, para D`Ambrósio (2004), já há uma compreensão de que a ideia de alfabetização como apenas habilidades de ler, escrever e contar são insuficientes para a formação do cidadão na atualidade. Nesse sentido, concordamos com esse autor quando relata que a mera alfabetização é insuficiente para uma formação que conduza ao pleno exercício da cidadania.

Assim como nos sugere Gee (2015), o Letramento, por se tratar de um conceito mais recente, ainda está em construção. Em sua obra "Social Linguistics and Literacies: Ideology in Discourses", o autor supra- 
mencionado nos estimula a repensar essas novas perspectivas, que decorrem naturalmente de sua complexidade em torno da abrangência de um novo campo de trabalho de diferentes disciplinas: a noção de letramento se amplia para prática social e ideológica, pois não pode ser vista como mera aquisição das habilidades de ler e escrever, já que há diferentes estilos de linguagem e usos em variadas propostas e ocasiões.

Segundo Gee (2015), o termo literacy, em língua inglesa, deu lugar à compreensão de um novo conceito fruto dos significados da natureza da linguagem. Nos países de língua inglesa, o termo literacy surgiu em face da necessidade de diferenciar as novas perspectivas sobre o papel da escrita na sociedade atual. No Brasil, o termo assinalado e discutido nas pesquisas foi letramento (KLEIMAN,1995; SOARES, 2009).

Frente a esta perspectiva, em solo brasileiro tem-se ampliado a concepção de Letramento Matemático. Fonseca (2004), em seu livro intitulado "Letramento no Brasil: Habilidades Matemáticas" aponta a partir dos resultados do INAF (Indicador Nacional de Alfabetismo Funcional) que, em 2002, com o foco nas habilidades matemáticas discutiu-se a perspectiva de alfabetismo funcional em Matemática como sendo a "capacidade de mobilização de conhecimentos associados à quantificação, à ordenação, à orientação e suas relações, operações e representações, na realização de tarefas ou na resolução de situações-problemas" (INAF, 2002, p. 6).

Toledo (2004) relaciona o alfabetismo funcional à ideia de Numeramento. Para esta autora, ser numerado envolve, justamente, ter algumas habilidades de Letramento, habilidades matemáticas e estar apto para combiná-las para o uso em situações de acordo com o que é requerido.

D`Ambrósio (2004, p. 36), por sua vez, apresenta os conceitos de Literacia como um instrumento comunicativo, sendo "[a] capacidade de processar informação escrita, o que inclui, leitura e cálculo, na vida cotidiana". Por seu turno, Materacia é um instrumento analítico que encerra "a capacidade de interpretar e manejar sinais e códigos e de propor e utilizar modelos na vida cotidiana" e Tecnoracia, um instrumento tecnológico como sendo "a capacidade de usar e combinar instrumentos, simples ou complexos, avaliando suas possibilidades, limitações e adequação a necessidade e situações" (D’AMBRÓSIO, 2004, p. 36). 
Nota-se que essas concepções têm proximidade com as ideias de Letramento abordadas por Soares (2003) e David (2004), que fazem relação aos níveis de habilidades funcionais com o que também denominam de Numeramento. Nesse sentido, considera-se que são as mesmas ideias de Letramento apresentadas por Soares aplicada à área da Matemática.

De acordo com Soares (2009), o termo Letramento pode ter sido usado pela primeira vez no Brasil no ano de 1986, por Mary Kato, no livro "No mundo da escrita: uma perspectiva psicolinguística".

Para Soares, a palavra letramento:

[...] é a versão para o português da palavra da língua inglesa litteracy. [...], que corresponde ao estado ou condição que assume aquele que aprende a ler e escrever. Implícita nesse conceito está a ideia de que a escrita traz consequências sociais, culturais, políticas, econômicas, cognitivas, linguísticas, quer para o grupo social em que seja introduzida, quer para o indivíduo que aprenda a usá-la [...] (SOARES, 1999, p. 17).

Soares apresenta em seus estudos uma perspectiva mais abrangente sobre o Letramento, o considerando como "o estado ou a condição de quem responde adequadamente as intensas demandas sociais pelo uso amplo e diferenciado da leitura e da escrita" (SOARES, 2003, 92).

A autora explica que:

Ao exercício efetivo e competente da tecnologia da escrita denomina-se letramento que implica habilidades variadas, tais como: capacidade de ler ou escrever para atingir diferentes objetivos - para informar-se, para interagir com outros, para imergir no imaginário, no estético, para ampliar conhecimentos, para seduzir ou induzir para divertir-se, para orientar-se, para apoio a memória, para catar-se [...]; habilidades de interpretar e produzir diferentes tipos e gêneros de textos, habilidades de orientar-se pelos protocolos de leitura que marcam o texto ou de lançar mão desses protocolos, ao escrever, atitudes de inserção efetiva no mundo da escrita, tendo interesse e prazer em ler e escrever, sabendo utilizar a escrita para encontrar para ou fornecer informações e conhecimentos, escrevendo ou lendo de forma diferenciada, segundo as circunstâncias, os objetivos, o interlocutor [...]. (SOARES, 2003, p. 92).

A partir dessa perspectiva, entendemos que o letramento propõe que façamos o uso social das regras da escrita, apresentando domínio sobre as habilidades de ler e escrever, diversificando a imaginação, fazendo 
bom uso da estética textual, interpretando e produzindo diferentes gêneros textuais e utilizando a escrita para coletar, organizar e fornecer informações e conhecimentos. A natureza relacional do letramento no domínio do trabalho docente possui um tom que deve recair sobre as práticas de gêneros textuais (KLEIMAN, 1995).

Em conformidade com as ideias de letramento, os gêneros textuais são permeados por uma linguagem plural da qual são veiculadas práticas diversas e necessidades comunicativas específicas (OLIVEIRA, 2010). Nesse sentido, a função social que a leitura e a escrita proporcionam no desenvolvimento das habilidades postas no trato a interpretação dos diferentes gêneros textuais com os quais nos deparamos no dia a dia são fundamentais para o desenvolvimento do letramento.

Destacamos que o letramento envolve leitura, e que para ser um bom leitor há a necessidade de se desenvolver um conjunto de habilidades, comportamentos e conhecimentos. A escrita também tem papel de destaque porque, por meio dela, são expressos processos de produção de conhecimento.

No processo de letramento é importante que os indivíduos desenvolvam autonomia para ler, interpretar e escrever seus próprios textos. Assim, por exemplo, crianças que escutam frequentemente histórias lidas por adultos, são capazes de pegar um livrinho e fingir que leem a história, usando para isso, a linguagem que é característica do letramento.

O letramento possui duas dimensões, que são a dimensão individual e a social. Na dimensão individual, o letramento é visto no âmbito pessoal, enquanto na dimensão social, é visto como um fenômeno cultural. No caso particular da Matemática, entendemos que muitas ações matemáticas incorporam as práticas sociais de leitura e escrita, que se adequam à perspectiva do letramento. Essas ações podem ser entendidas como um esboço pertinente às habilidades e práticas trabalhadas no desenvolvimento do conhecimento matemático.

Desta forma, associa-se que:

Letramento matemático é a capacidade individual de formular, empregar, e interpretar a matemática em uma variedade de contextos. Isso inclui raciocinar matematicamente e utilizar conceitos, procedimentos, fatos e ferramentas matemáticas para descrever, explicar e predizer fenômenos. Isso auxilia os indivíduos a reconhecer o papel que a matemática 
exerce no mundo e para que cidadãos construtivos, engajados e reflexivos possam fazer julgamentos bem fundamentados e tomar as decisões necessárias (OECD/PISA, 2012, p. 18).

A OECD/PISA ${ }^{4}$ aborda o letramento matemático como sendo a capacidade de um indivíduo de identificar e atender o papel que a Matemática representa no mundo, sabendo utilizar esse conhecimento de forma que satisfaça as suas necessidades gerais do cotidiano do indivíduo.

\section{Para Fonseca,}

A opção pelo uso do termo letramento em função da concepção de "habilidades matemáticas como constituintes das estratégias de leitura que precisam ser implementadas para uma compreensão da diversidade de textos que a vida social nos apresenta com frequência e diversificação cada vez maiores" (FONSECA, 2004, p. 27).

Essa concepção reflete a perspectiva de letramento incorporada a uma visão mais ampla das práticas sociais de uso da Matemática, relacionando-se com o uso mais abrangente e funcional dessa área do conhecimento, o que exige do estudante a capacidade de reconhecer e formular problemas matemáticos em variadas situações de sua vida.

As concepções apresentadas nos permitem dizer que o Letramento Matemático é o resultado de uma aprendizagem, e por isso pode ser atribuído a diferentes contextos, de acordo com os objetivos a serem alcançados.

Na perspectiva adotada pelo PISA (2012) são apresentadas sete capacidades tidas como essenciais para que o estudante se torne letrado em Matemática. Capacidades estas que são elencadas da seguinte maneira:

- Comunicação: O Letramento Matemático envolve comunicação. O indivíduo percebe a existência de algum desafio e é estimulado a reconhecer e compreender uma situação-problema. A leitura, decodificação e interpretação de declara-

\footnotetext{
4. PROGRAMME FOR INTERNATIONAL STUDENT ASSESSMENT (PISA): O PISA é um estudo internacional sobre os conhecimentos e as competências dos alunos de 15 anos realizado em vários países industrializados.
} 
ções, perguntas, tarefas ou objetos habilita o indivíduo a formar um modelo mental da situação, o que é um passo importante na compreensão, esclarecimento e formulação de um problema. Durante o processo de resolução, os resultados intermediários podem precisar ser resumidos e apresentados. Mais tarde, uma vez que uma solução tenha sido encontrada, o estudante pode precisar apresentar a solução de um problema, e talvez, uma explicação ou justificativa para outros.

- Matematizar: O Letramento Matemático pode envolver a transformação de um problema definido no mundo real para uma forma estritamente matemática (que pode incluir estruturação, conceituação, fazer suposições, e/ ou formulação de um modelo), ou interpretar ou avaliar um resultado matemático ou um modelo matemático em relação ao problema original. O termo "matematizar" é utilizado para descrever as atividades matemáticas fundamentais envolvidas.

- Representação: O Letramento Matemático envolve muito frequentemente representações de objetos matemáticos e situações. Isto pode implicar na seleção, interpretação, tradução entre e usando uma variedade de representações para capturar uma situação, interagir com um problema, ou para apresentar o seu próprio trabalho. As representações podem incluir gráficos, tabelas, diagramas, figuras, equações, fórmulas, e materiais concretos.

- Raciocínio e argumentação: Uma habilidade matemática que é chamada em todas as diferentes fases (estágios) e atividades associadas com Letramento Matemático é conhecida como raciocínio e argumentação. Essa capacidade envolve processos de pensamento logicamente enraizados que exploram e vinculam elementos de problemas, de modo a fazer inferências, analisar justificativas, ou formular justificativas sobre uma afirmação ou na solução de problemas.

- Delinear estratégia para Resolução de Problemas: O Letramento Matemático frequentemente requer o delineamento de estratégias para resolução de problemas matemáticos. Isso envolve um conjunto de processos críticos de 
controle que norteiam um indivíduo para efetivamente reconhecer, formular e resolver problemas. Esta habilidade é caracterizada como seleção ou delineamento de um plano ou estratégia de usar a Matemática para resolver problemas decorrentes de uma tarefa ou contexto, bem como orientar a sua execução. Essa capacidade matemática pode ser exigida em qualquer das etapas do processo de resolução de problemas.

- Uso de linguagem simbólica, formal e técnica, e operações: O Letramento Matemático requer o uso de linguagem simbólica, formal e técnica, e operações. Isso envolve compreensão, interpretação, manipulação e fazer uso de expressões simbólicas dentro de um contexto matemático (incluindo expressões aritméticas e operações) regido por convenções e regras matemáticas. Isto também envolve compreensão e utilização de constructos formais baseados em definição, regras e sistemas formais, bem como utilizar algoritmos com estes conceitos. Os símbolos, regras e sistemas utilizados variam de acordo com qual conteúdo particular da Matemática será necessário para uma específica tarefa de formular, resolver ou interpretar matemática.

- Utilizar Ferramentas Matemáticas: As Ferramentas Matemáticas compreendem instrumentos como os de medida, ou calculadoras e computadores. Esta habilidade envolve conhecer e estar apto para lidar com várias ferramentas que podem auxiliar na atividade matemática, bem como saber das limitações desses instrumentos. Ferramentas matemáticas também possuem um importante papel na comunicação dos resultados. A prova em computador amplia as possibilidades para os estudantes utilizarem ferramentas matemáticas.

A partir destas capacidades, o PISA (2012) propõe a avaliação do letramento em Matemática por meio de três dimensões:

$\checkmark \quad$ O conteúdo de Matemática, definido primeiramente em termos de conceitos matemáticos mais amplos (como estimativa, mudança e crescimento, espaço e forma, raciocínio 
lógico, incerteza e dependências e relações), e secundariamente em relação a ramos do currículo (como relações numéricas, álgebra, geometria e tratamento da informação);

$\checkmark \quad$ processo da Matemática, definido pelas competências matemáticas gerais. Essas incluem o uso da linguagem matemática, escolha de modelos e procedimentos e habilidades de resolução de problemas. No entanto, a ideia não é separar essas habilidades em diferentes itens de teste, já que se pressupõe que uma série de competências será necessária para desempenhar qualquer tarefa matemática. Essas competências são organizadas em três classes: a primeira consiste na realização de operações simples; a segunda exige o estabelecimento de conexões para resolver problemas; a terceira consiste de raciocínio matemático, generalização e descobertas, e exige que os alunos façam análises, identifiquem elementos matemáticos de uma dada situação e proponham problemas;

$\checkmark$ Os contextos, compreendidos como as situações nas quais a Matemática é usada, variando de contextos particulares àqueles relacionados com questões científicas e públicas mais amplas.

Portanto, para um indivíduo ser considerado letrado em Matemática, é necessário que ele saiba identificar e entender o papel que a Matemática representa no mundo, de forma que esta venha atender as suas necessidades gerais.

As capacidades cognitivas estão disponíveis ou podem ser desenvolvidas pelos indivíduos, a fim de compreender e interagir com o mundo de forma matemática, ou para resolver problemas. À medida que aumenta seu nível de letramento em matemática, o indivíduo é capaz de desenvolver cada vez mais as capacidades fundamentais nessa área. Assim, um maior número dessas capacidades matemáticas é demandado à medida que aumenta a dificuldade do item (OECD/PISA, 2012, p. 24).

O estabelecimento de uma série de capacidades, conforme explicitado anteriormente, permite realizar um diagnóstico do aluno em razão das competências e habilidades que ele consegue mobilizar em diversas situações. 
Concernentes à Base Nacional Comum Curricular (BNCC), fundamentando-nos nos processos de Letramento Matemático, é que aqui revisitaremos algumas implicações para o ensino. Diante disso, a perspectiva de Letramento explorada na BNCC é que, a partir de sua aprovação, esta passa a ser um importante instrumento para o planejamento das ações atreladas ao ensino de Matemática para a Educação Básica.

A BNCC é um documento plural, contemporâneo, e estabelece com clareza o conjunto de aprendizagens essenciais e indispensáveis a que todos os estudantes, crianças, jovens e adultos têm direito. Com ela, redes de ensino e instituições escolares públicas e particulares passam a ter uma referência nacional obrigatória para a elaboração ou adequação de seus currículos e propostas pedagógicas. Essa referência é o ponto ao qual se quer chegar a cada etapa da Educação Básica.

Para a Educação Básica, as aprendizagens essenciais definidas na BNCC devem assegurar aos estudantes o desenvolvimento de dez competências gerais, que indicam, na esfera pedagógica, os direitos à aprendizagem. Cada área de conhecimento estabelece competências específicas de área. Essas competências específicas contribuem com as competências gerais no intuito de alcançar os objetivos do documento. As competências específicas possibilitam a articulação horizontal entre as áreas, perpassando todos os componentes curriculares, e também a articulação vertical, ou seja, a progressão entre o Ensino Fundamental Anos Iniciais e o Ensino Fundamental Anos Finais.

Vale ressaltar que as competências propostas pela BNCC se intitulam um conjunto de conhecimentos, habilidades, valores e atitudes que buscam promover o desenvolvimento dos estudantes em todas as suas dimensões: intelectual, física, social, emocional e cultural.

A BNCC de 2017 trata o Letramento Matemático a partir da definição dada pelo Programme for International Student AssessmentPISA, definição esta tratada anteriormente. Nesse sentido, para o desenvolvimento das competências e habilidades propostas pela BNCC baseadas no PISA, é importante o compromisso de que a escola o priorize, a partir das atividades desenvolvidas em sala de aula pelos professores e alunos, pois é na escola que acontecem as interações que possibilitam a consolidação do aprendizado, e desenvolvimento do sujeito aprendiz.

Desta forma, consolidando o aprendizado pelo viés das competências e habilidades, que são conceitos que possuem relação entre si, o 
ensino teria maior sucesso. Pois, habilidade é o saber fazer, é conseguir pôr em prática as teorias e conceitos mentais que foram adquiridos. Conforme Perrenoud (1999, p. 5), "habilidade trata-se de uma sequência de modos operatórios, de induções e deduções, onde são utilizados esquemas de alto nível". Enquanto a competência é mais ampla e consiste na junção e coordenação de conhecimentos, atitudes e habilidades: "competência é a capacidade de agir eficazmente em um determinado tipo de situação, apoiada em conhecimentos, mas sem limitar-se a eles" (PERRENOUD, 1999, p. 7).

Na BNCC (2017) destacam-se, ainda, o raciocínio, a representação, a comunicação e a argumentação como processos de aprendizagem potencialmente ricos para o desenvolvimento de competências fundamentais para o desenvolvimento do Letramento Matemático.

Nessa perspectiva, o Letramento Matemático se constitui como uma ação-reflexão que se preocupa com as diversificadas práticas socioculturais de leitura, escrita, interpretação, argumentação, visualização e raciocínio que envolvem os sujeitos no contexto escolar e fora dele.

Desta forma, na área de Matemática, a BNCC apresenta oito competências específicas para o Ensino Fundamental, a saber:

- Reconhecer que a Matemática é uma ciência humana, fruto das necessidades e preocupações de diferentes culturas, em diferentes momentos históricos, e é uma ciência viva, que contribui para solucionar problemas científicos e tecnológicos e para alicerçar descobertas e construções, inclusive com impactos no mundo do trabalho.

- Desenvolver o raciocínio lógico, o espírito de investigação e a capacidade de produzir argumentos convincentes, recorrendo aos conhecimentos matemáticos para compreender e atuar no mundo.

- Compreender as relações entre conceitos e procedimentos dos diferentes campos da Matemática (Aritmética, Álgebra, Geometria, Estatística e Probabilidade) e de outras áreas do conhecimento, sentindo segurança quanto à própria capacidade de construir e aplicar conhecimentos matemáticos, desenvolvendo a autoestima e a perseverança na busca de soluções.

- Fazer observações sistemáticas de aspectos quantitativos e qualitativos presentes nas práticas sociais e culturais, de modo a 
investigar, organizar, representar e comunicar informações relevantes, para interpretá-las e avaliá-las crítica e eticamente, produzindo argumentos convincentes.

- Utilizar processos e ferramentas matemáticas, inclusive tecnologias digitais disponíveis, para modelar e resolver problemas cotidianos, sociais e de outras áreas de conhecimento, validando estratégias e resultados.

- Enfrentar situações-problema em múltiplos contextos, incluindo-se situações imaginadas, não diretamente relacionadas com o aspecto prático-utilitário, expressar suas respostas e sintetizar conclusões, utilizando diferentes registros e linguagens (gráficos, tabelas, esquemas, além de texto escrito na língua materna e outras linguagens para descrever algoritmos, como fluxogramas, e dados).

- Desenvolver e/ou discutir projetos que abordem, sobretudo, questões de urgência social, com base em princípios éticos, democráticos, sustentáveis e solidários, valorizando a diversidade de opiniões de indivíduos e de grupos sociais, sem preconceitos de qualquer natureza.

- Interagir com seus pares de forma cooperativa, trabalhando coletivamente no planejamento e desenvolvimento de pesquisas para responder a questionamentos e na busca de soluções para problemas, de modo a identificar aspectos consensuais ou não na discussão de uma determinada questão, respeitando o modo de pensar dos colegas e aprendendo com eles (BRASIL, 2017, p. 265).

Para a proposta neste artigo, nos pautaremos na análise dessas competências.

\section{Percursos Metodológicos}

Para este estudo adotamos o conceito de Letramento Matemático em conformidade com o proposto pelo programa de avaliação estudantil da OECD/PISA e, a partir de seus pressupostos, analisamos os pontos das características desses conceitos que foram contempladas pela BNCC (2017) por meio de suas oito competências específicas de Matemática para o Ensino Fundamental.

Recorremos à pesquisa de cunho qualitativo por considerarmos que suas características seriam pertinentes para nossa análise, uma vez que, 


\begin{abstract}
Ao optar pela pesquisa qualitativa, o professor/pesquisador pode utilizar várias técnicas de coleta de dados e várias estratégias para registrar e analisar os dados. Os dados podem tomar a forma de transcrições de entrevistas gravadas com o uso do gravador, anotações de campo em protocolos de observação, diário de campo das intervenções do dia a dia na sala de aula, documentos, fotografias e outras representações gráficas (MOREIRA e CALEFE, 2008, p. 165).
\end{abstract}

De acordo com Bardin (2016), por meio de tal metodologia é possível fazer o tratamento do conteúdo de forma a apresentá-lo de maneira diferente no âmbito dos métodos e técnicas. Para tanto, recorremos ao que preconiza a autora sobre a analise de conteúdo como "um conjunto de técnicas de análise das comunicações que utiliza procedimentos sistemáticos e objetivos de descrição do conteúdo das mensagens" (BARDIN, 2016, p. 44). Conforme nos mostra na figura 1, a seguir a relação esquemática proposta por Bardin (2016):

Figura 1. Desenvolvimento de uma análise

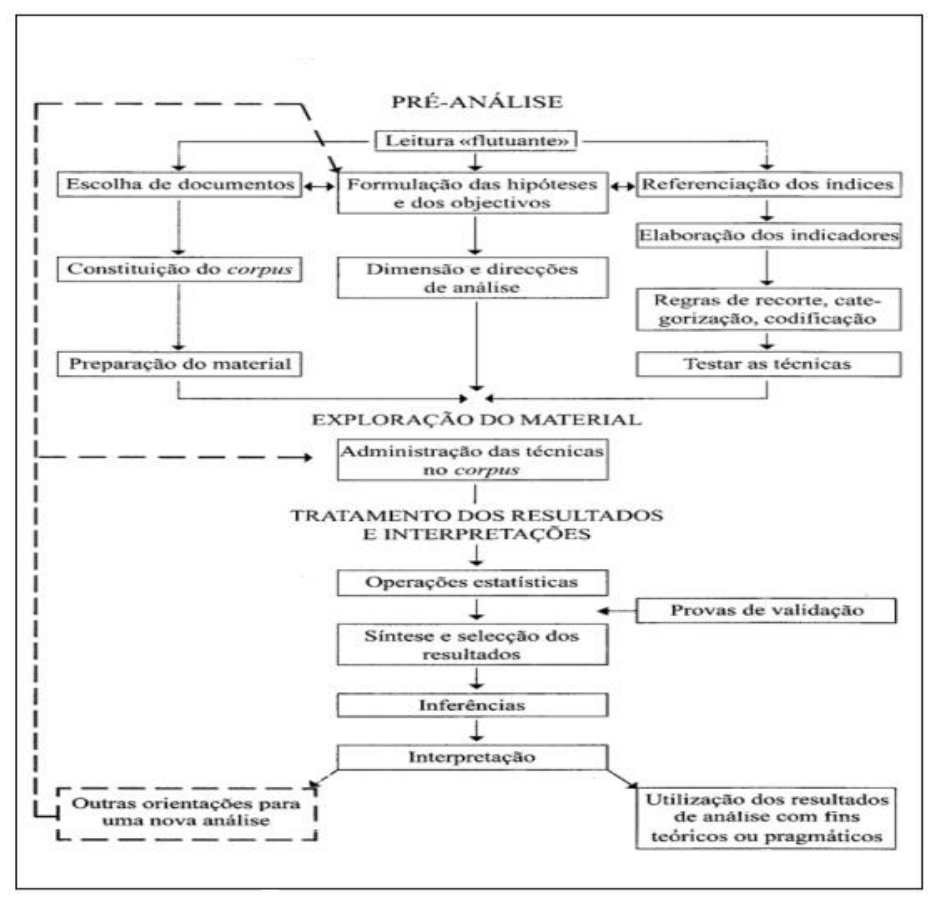

Fonte: BARDIN, 2016, p. 132. 
Em nosso estudo, o olhar foi direcionado aos aspectos relativos ao Letramento Matemático presentes nas competências de Matemática propostas pela BNCC.

\section{Quadro resumido das análises observadas}

O objetivo de levantar os argumentos aqui apontados não esgota a temática e nem despreza a continuidade de pesquisas acerca do tema proposto. Todavia, os argumentos reunidos implicam o questionamento se tais eventos, verdadeiramente, tomados ou aprendidos na formação escolar. Entendemos que a formação profissional precisa ser considerada como ponto de partida para a importância das colocações aqui sugeridas. Logo, consideramos que a Educação deve-se voltar para novos parâmetros e repensar, constantemente, a adoção da relação conflituosa e necessária entre a teoria e a prática.

Para observamos melhor essas implicações, elaboramos dois quadros com o intuito de subsidar nossas análises, nos qual se especificou: a) Competências preconizadas pela Matemática BNCC do Ensino Fundamental ; b) Elementos de Letramento Matemático (PISA) e c) relações/apontamentos observados.

O primeiro quadro (ver Quadro 1) refere-se à influência de apenas um elemento de letramento (PISA) em articulação com a BNCC. Desta maneira, não se pode negar que, quanto mais aspectos interligados, mais conteúdos específicos se apresentam e se desdobram. 
Quadro 1. Síntese das análises atrelado a cada elemento do letramento

\begin{tabular}{|c|c|c|}
\hline $\begin{array}{c}\text { Competências preconizadas } \\
\text { pela BNCC }\end{array}$ & $\begin{array}{c}\text { Elementos } \\
\text { de Letra- } \\
\text { meto } \\
\text { (PISA) } \\
\end{array}$ & Relações/apontamentos \\
\hline $\begin{array}{l}\text { (1) Reconhecer que a Matemática } \\
\text { é uma ciência humana, fruto das } \\
\text { necessidades e preocupações de } \\
\text { diferentes culturas, em diferentes } \\
\text { momentos históricos, e é uma ci- } \\
\text { ência viva, que contribui para so- } \\
\text { lucionar problemas científicos e } \\
\text { tecnológicos e para alicerçar des- } \\
\text { cobertas e construções, inclusive } \\
\text { com impactos no mundo do traba- } \\
\text { lho. }\end{array}$ & \multirow[t]{2}{*}{$\begin{array}{l}\text { Comunica- } \\
\text { ção }\end{array}$} & $\begin{array}{l}\text { Reconhecimento da Matemática } \\
\text { como fruto de uma construção so- } \\
\text { cial a partir das necessidades indivi- } \\
\text { duais e coletivas para a resolução de } \\
\text { problemas necessários para o } \\
\text { avanço da sociedade. }\end{array}$ \\
\hline $\begin{array}{l}\text { (8) Interagir com seus pares de } \\
\text { forma cooperativa, trabalhando } \\
\text { coletivamente no planejamento e } \\
\text { desenvolvimento de pesquisas } \\
\text { para responder a questionamentos } \\
\text { e na busca de soluções para pro- } \\
\text { blemas, de modo a identificar as- } \\
\text { pectos consensuais ou não na dis- } \\
\text { cussão de uma determinada ques- } \\
\text { tão, respeitando o modo de pensar } \\
\text { dos colegas e aprendendo com } \\
\text { eles. }\end{array}$ & & $\begin{array}{l}\text { A capacidade de comunicação con- } \\
\text { tribui para o processo de idenfifica- } \\
\text { ção de questões que tem potencial } \\
\text { para a pesquisa, bem como nos ha- } \\
\text { bilita a partir do trabalho coletivo a } \\
\text { desenvolver estratégias para respon- } \\
\text { der a tais questionamentos a partir } \\
\text { de procedimentos científicos. }\end{array}$ \\
\hline $\begin{array}{l}\text { (2) Desenvolver o raciocínio ló- } \\
\text { gico, o espírito de investigação e a } \\
\text { capacidade de produzir argumen- } \\
\text { tos convincentes, recorrendo aos } \\
\text { conhecimentos matemáticos para } \\
\text { compreender e atuar no mundo. }\end{array}$ & $\begin{array}{l}\text { Raciocínio } \\
\text { e argumen- } \\
\text { tação }\end{array}$ & $\begin{array}{l}\text { Capacidade de entender e atuar no } \\
\text { mundo por meio do desenvolvi- } \\
\text { mento de raciocínio lógico, capaz de } \\
\text { compreender e resolver problemas } \\
\text { bem como ter habilidade de argu- } \\
\text { mentar suas ideias a partir de conhe- } \\
\text { cimentos matemáticos. }\end{array}$ \\
\hline $\begin{array}{l}\text { (5) Utilizar processos e ferramen- } \\
\text { tas matemáticas, inclusive tecno- } \\
\text { logias digitais disponíveis, para } \\
\text { modelar e resolver problemas co- } \\
\text { tidianos, sociais e de outras áreas } \\
\text { de conhecimento, validando estra- } \\
\text { tégias e resultados. }\end{array}$ & $\begin{array}{l}\text { Utilizar fer- } \\
\text { ramentas } \\
\text { matemáti- } \\
\text { cas }\end{array}$ & $\begin{array}{l}\text { Reconhecimento da importancia de } \\
\text { fazer uso das ferramentas disponí- } \\
\text { veis para a solução de problemas ou } \\
\text { aprimoramento de soluções anterio- } \\
\text { res. }\end{array}$ \\
\hline
\end{tabular}

Fonte: Elaborado pelo autor deste artigo.

No quadro 2 evidenciamos a influência de dois ou mais elementos do letramento com as competências previstas na BNCC. 
Quadro 2. Síntese das análises relativas a dois ou mais elementos de letramento

\begin{tabular}{|c|c|c|}
\hline $\begin{array}{c}\text { Competências preconizadas } \\
\text { pela BNCC }\end{array}$ & $\begin{array}{l}\text { Elementos de } \\
\text { Letrameto } \\
\text { (PISA) }\end{array}$ & Relações/apontamentos \\
\hline $\begin{array}{l}\text { (3) Compreender as relações entre } \\
\text { conceitos e procedimentos dos di- } \\
\text { ferentes campos da Matemática } \\
\text { (Aritmética, Álgebra, Geometria, } \\
\text { Estatística e Probabilidade) e de } \\
\text { outras áreas do conhecimento, } \\
\text { sentindo segurança quanto à pró- } \\
\text { pria capacidade de construir e } \\
\text { aplicar conhecimentos matemáti- } \\
\text { cos, desenvolvendo a autoestima e } \\
\text { a perseverança na busca de solu- } \\
\text { ções. }\end{array}$ & $\begin{array}{l}\text { Matematizar; } \\
\text { Representa- } \\
\text { ção; } \\
\text { Delinear estra- } \\
\text { tégia para Re- } \\
\text { solução de } \\
\text { Prolemas }\end{array}$ & $\begin{array}{l}\text { A segurança para a busca de so- } \\
\text { luções de problemas cotidianos } \\
\text { perpassa por transformá-lo para o } \\
\text { contexto matemático (modelo), } \\
\text { estabeler conexões entre as dife- } \\
\text { rentes representações e a criação } \\
\text { e análise de estratégias para re- } \\
\text { solve-lo. }\end{array}$ \\
\hline $\begin{array}{l}\text { (4) Fazer observações sistemáticas } \\
\text { de aspectos quantitativos e quali- } \\
\text { tativos presentes nas práticas soci- } \\
\text { ais e culturais, de modo a investi- } \\
\text { gar, organizar, representar e co- } \\
\text { municar informações relevantes, } \\
\text { para interpretá-las e avaliá-las crí- } \\
\text { tica e eticamente, produzindo ar- } \\
\text { gumentos convincentes. }\end{array}$ & $\begin{array}{l}\text { Comunicação; } \\
\text { Raciocínio e } \\
\text { argumentação }\end{array}$ & $\begin{array}{l}\text { Saber fazer a leitura crítica de } \\
\text { práticas socialmente construídas } \\
\text { para poder interpretá-las e inter- } \\
\text { vir nessa realidade por meio de } \\
\text { argumentos bem elaborados a } \\
\text { partir de conhecimentos matemá- } \\
\text { ticos. }\end{array}$ \\
\hline $\begin{array}{l}\text { (7) Desenvolver e/ou discutir pro- } \\
\text { jetos que abordem, sobretudo, } \\
\text { questões de urgência social, com } \\
\text { base em princípios éticos, demo- } \\
\text { cráticos, sustentáveis e solidários, } \\
\text { valorizando a diversidade de opi- } \\
\text { niões de indivíduos e de grupos } \\
\text { sociais, sem preconceitos de qual- } \\
\text { quer natureza. }\end{array}$ & & $\begin{array}{l}\text { O raciocínio fundamentado em } \\
\text { conceitos científicos bem elabo- } \\
\text { rados levam a argumentos que } \\
\text { podem contribuir de forma demo- } \\
\text { crática para a discussão de proje- } \\
\text { tos de interesse social. }\end{array}$ \\
\hline $\begin{array}{l}\text { (6) Enfrentar situações-problema } \\
\text { em múltiplos contextos, inclu- } \\
\text { indo-se situações imaginadas, não } \\
\text { diretamente relacionadas com o } \\
\text { aspecto prático- utilitário, expres- } \\
\text { sar suas respostas e sintetizar con- } \\
\text { clusões, utilizando diferentes re- } \\
\text { gistros e linguagens (gráficos, ta- } \\
\text { belas, esquemas, além de texto es- } \\
\text { crito na língua materna e outras } \\
\text { linguagens para descrever algorit- } \\
\text { mos, como fluxogramas, e dados). }\end{array}$ & $\begin{array}{l}\text { Matematizar; } \\
\text { Uso de Lin- } \\
\text { guagem sim- } \\
\text { bólica, formal } \\
\text { e técna, e ope- } \\
\text { rações }\end{array}$ & $\begin{array}{l}\text { Modelar e resolver problemas por } \\
\text { meio dos procedimentos, concei- } \\
\text { tos, representações e linguagens } \\
\text { oriundas da Matemática. }\end{array}$ \\
\hline
\end{tabular}




\section{Análises das Competências da BNCC na Perspectiva do Le- tramento Matemático}

Em relação ao apresentado no quadro 1 percebemos que um fator que se sobressai dessa interpretação é o foco na comunicação, que está relacionado aos pontos 1 e 8 das competências da BNCC. O uso desse termo, sobretudo em Educação, entre outras orientações, configura a adoção de novas estratégias de aprendizagens. Como constatação de tal ponto destacamos a passagem: "identificar aspectos consensuais ou não na discussão de uma determinada questão" (BNCC, 2017, p. 267).

Em relação ao eixo 5 com o elemento letramento do PISA - "utilizar ferramentas matemáticas" -, podemos observar a inserção do tema sobre o eixo de novas tecnologias da informação e comunicação, que, por sinal, tem ganhado na atualidade destaque e mesmo centralidade de pesquisas, graças à implementação (ainda que gradual e lenta) das ferramentas computacionais no ensino de Matemática (BORBA; SCUCUGLIA; GADANIDIS, 2014); BORBA; ALMEIDA; CHIARI, 2015; ROSA; MUSSATO, 2015).

Ao que nos parece, a tendência das TICs permeia fortemente os currículos, ainda que se encontre no ensino uma amarra aos enfoques a às metodologias mais tradicionais, ou a dificuldade da entrada de ferramentas e equipamentos necessários na escola. Por isso, cumpre ressaltar que o que se deseja em termos de características mais fundamentais é o acesso aos equipamentos que fazem cumprir essas metas.

De acordo com os Parâmetros Curriculares Nacionais de Matemática (1997) foi a partir da década de 80, com a realização do National Council of Teachers of Mathematics - NCTM nos Estados Unidos que se intensificaram as recomendações para o ensino de Matemática por meio do documento "Agenda para Ação". Este documento influenciou as reformas curriculares no mundo inteiro. Destaca-se que, dentre os pontos de convergêngia entre os diferentes países, no que se refere ao ensino de Matemática, um deles foi justamente a "necessidade de levar os alunos a compreenderem a importância do uso da tecnologia e a acompanharem sua permanente renovação" (BRASIL, 1997, p. 21).

Em relação aos Parâmetros estabelecidos no Brasil por meios dos PCNS (1996, p. 26), destaca-se que "o mundo do trabalho requer pessoas preparadas para utilizar diferentes tecnologias e linguagens (que 
vão além da comunicação oral e escrita), instalando novos ritmos de produção, de assimilação rápida de informações, resolvendo e propondo problemas em equipe". De acordo com os PCNs,

Nesse cenário, insere-se mais um desafio para a escola, ou seja, o de como incorporar ao seu trabalho, apoiado na oralidade e na escrita, novas formas de comunicar e conhecer. Por outro lado, também é fato que o acesso a calculadoras, computadores e outros elementos tecnológicos já é uma realidade para parte significativa da população (BRASIL, 1997, p.34).

Para Machado, Ferreira e Marcelino (2019), as tecnologias digitais, a cada dia, ganham mais espaço em atividades cotidianas e esta realidade se estende às escolas, uma vez que o uso de celulares e tablets por exemplo, está presente na vida dos alunos e esses hoje pensam com a tecnologia. Para os autores:

No entanto, a utilização dessas tecnologias no ambiente escolar ainda se apresenta como um desafio a ser superado, uma vez que há divergências com a cultura escolar que muitas vezes perpetua a ideia de que as tecnologias podem desviar a atenção dos alunos ou que pode substituir o pensar humano (MACHADO; FERREIRA; MARCELINO, 2019, p. 425).

No entanto Machado, Ferreira e Marcelino (2019) destacam a importância do uso das TICs para o ensino de Matemática, já que na própria BNCC (2017) o uso da tecnologia é um instrumento que pode possibilitar uma maior autonomia dos alunos, propiciando outras formas de pensar, refletir e criar conjecturas que contribuam para o ensino da Matemática.

Com relação ao Quadro 2, o termo comunicação voltou a aparecer, estando mais relacionado ao comportamento do que é observável ou como uma meta principal a ser atingida. Neste sentido, vale ressaltar que aquilo que é reconhecido como esforço da humanidade, cremos ser, na verdade, um grande desafio de nossa sociedade.

Percebemos o crescente aumento de pesquisas que têm como foco a comunicação e a argumentação, sobretudo, do enfoque que deve ser tomado inclusive no raciocínio e o valor a ser adquirido por tais práticas.

Como é possivel depreender, os princípios que norteiam a BNCC e o PISA permitem uma aproximação da noção de habilidades comunicativas com o ideário de política educacional. Essas justificativas para as 
mudanças no Ensino Fundamental, todavia, encontram também críticos de correntes e aspirações construtivistas.

A partir dos Quadros 1 e 2, observamos que a primeira competência destaca a importância que a Matemática teve, e ainda tem, no desenvolvimento histórico, cultural e tecnológico da humanidade, atuando para atender às diversas necessidades dos indivíduos, pois concebe esse conhecimento como uma ciência em construção a partir dos anseios e das necessidades sociais.

Nessa perspectiva, entendemos que esta competência tem relação com o elemento do Letramento Matemático que trata da comunicação, pois se reconhece que esta é indispensável para que o indivíduo possa estabelecer uma interlocução do meio em que vive com o meio que aspira a conhecer, tendo como integrante o conhecimento matemático, haja vista que a comunicação, na perspectiva do Letramento Matemático, propõe que o aluno saiba compreender e manejar a extensão e os limites dos conceitos matemáticos para que possa fazer o melhor uso da Matemática nas suas necessidades diárias.

Notamos que tal perspectiva também tem alinhamento com a ideia de Literacia de D'Ambrósio (2004), quando aponta a comunicação como elemento fundamental, uma vez que por meio dela se desenvolve a capacidade de processar informações, sejam elas de escrita, de leitura e de cálculos na vida cotidiana. Essa característica, a partir de nossa análise, tem papel fundamental para a concepção da Matemática enquanto ciência fruto da construção humana e não como ciência pronta e acabada.

Na segunda competência, notamos a preocupação para que os alunos reconheçam o papel da Matemática na sociedade e que desenvolvam raciocínio e argumentos para entender e atuar no mundo.

Podemos perceber, portanto, uma relação direta com elemento do letramento matemático raciocínio e argumentação, uma vez que o Letramento Matemático explora o incentivo para que o aluno desenvolva a liberdade para pensar e fazer considerações sobre questões que envolvam conceitos matemáticos, bem como fazer as considerações pertinentes, proporcionando um ambiente possível de troca de informações e de busca para a solução de problemas. 
Essa capacidade de argumentação vem ao encontro dos próprios anseios de Letramento propostos por Soares (2003, p. 92), que destaca que em uma visão mais abrangente caracteriza "o estado ou condição de quem responde adequadamente as imensas demandas sociais pelo uso amplo e diferenciado da leitura e da escrita". Assim, fazemos a inferência de que, quando trata de uso diferenciado da leitura e escrita, uma das características a ser levada em consideração é justamente a argumentação, pois, por meio dela, há a possibilidade do estabelecimento do debate entre diferentes perspectivas, o que a nosso ver contribui para a construção da ciência e, consequentemente, para a resolução de problemas oriundos dos anseios sociais.

Nesse sentido, notamos potencial na BNCC para o empreendimento de um trabalho em sala de aula que propicie o desenvolvimento intelectual dos alunos, promovendo conhecimentos que podem levar os alunos a deixarem sua posição passiva frente ao seu processo de aprendizagem e passarem a ocupar posição mais ativa, que perpasse o processo de apenas compreender conceitos, mas também que desenvolva ações de propor e testar soluções em situações cotidianas. O aluno também é motivado a interagir, assumindo um papel mais participativo na sociedade, de forma que ele seja capaz de construir e expor argumentos, expressando seus princípios e valores.

Com isso, consideram-se essenciais essas ações interligadas pelas competências, para a formação de alunos capazes de serem considerados letrados em Matemática. É necessária a superação de um modelo ensino reprodutivista, e, nesse sentido, o Letramento Matemático pode ser uma possibilidade de superarmos esse modelo de ensino fortemente marcado pela repetição e a memorização.

Na competência 3, evidenciada no quadro, notamos que o foco está na importância em se estabelecer relações entre conceitos e procedimentos da Matemática, a fim de propiciarmos segurança nos processos de resolução de problemas. Para isso, é preciso haver conexões com três elementos do Letramento Matemático. Inicialmente, destacamos o matematizar, uma vez que este destaca a importância de se criar modelos matemáticos para interpretação e resolução de problemas cotidianos. Observa-se que para tal criação será fundamental o estabelecimento de conexões entre conceitos e procedimentos matemáticos e suas relações com as outras áreas do conhecimento que circundarão o problema a ser resolvido. 
Outro elemento que evidenciamos é a representação, uma vez que, para se estabelecer relações internas e externas, a Matemática lida com as diferentes representações e, por isso se mostra uma tarefa fundamental. Neste ínterim, são apresentadas características importantes, tais como, seleção e interpretação de dados para entender e interagir com uma situação posta. Ainda, notamos relações com a capacidade de delinear estratégia para Resolução de Problemas, uma vez que esta capacidade demanda a necessidade de se envolver um conjunto de processos críticos de controle que serão fundamentais para nortear as pessoas para que possam reconhecer formular e resolver problemas. Desta maneira, entendemos que, para isso, há de se ter um conhecimento amplo de conceitos e procedimentos para poder articulá-los nesse processo de entendimento e resolução de problemas.

Na competência 4, também observada no quadro, notamos a preocupação com a formação de um aluno que seja capaz de produzir argumentos pautados na observação sistemática de fenômenos qualitativos e quantitativos e que perpasse pelos processos de investigação, organização representação para que, assim, tenha condições de se comunicar com seus pares. Destacamos, aqui, o que a nosso ver é um grande desafio para a área de ensino de Matemática, pois traz um contraponto ao modelo de ensino marcado por um olhar instrumental da matemática, trazendo as características de ensino por meio da pesquisa para o Ensino Fundamental.

Estas observações nos remetem a duas características do Letramento Matemático: na comunicação, destacamos que o processo de leitura, decodificação e interpretação de declarações, perguntas, tarefas ou objetos é fundamental para a compreensão, esclarecimento e formulação de um problema e que a formulação de problemas se constitui como ponto crucial para o processo investigativo. Outro ponto de comunicação que destacamos é a capacidade de comunicar os seus resultados por meio de argumentos e justificativas bem fundamentadas. Esta visão de comunicação representa aspectos essenciais identificados na literatura por Ponte e colaboradores (2014) no desenvolvimento profissional de professores de matemática.

Esse último ponto é reforçado na característica que trata de raciocínio e argumentação, tendo em vista que trata justamente da capacidade de envolver processos de desenvolvimento de ideias que tenham fundamentos lógicos que explorem e estabeleçam vínculos com elementos do 
problema inicial, dando condições para fazer inferências, como verificar justificativas apresentadas e também apresentar suas justificativas a partir de afirmações prévias. Esses elementos combinados são fundamentais para a formação de um aluno investigador como o proposto na competência (4).

Na competência (5) observamos uma relação direta com a característica utilizar ferramentas matemáticas, uma vez que nesta destacase a importância do uso das ferramentas disponíveis o trabalho com atividades matemáticas, envolvendo a capacidade de conhecer, estar apto a utilizá-las, bem como ter condições de reconhecer suas potencialidades e limitações. Para tal, a BNCC destaca o papel das tecnologias digitais como ferramentas atuais tanto de tratamento e análise, como de comunicação de dados.

Esta característica também já havia sido ressaltada por D'Ambrósio (2004), quando aponta sua perspectiva de tecnoracia como um instrumento tecnológico que visa, justamente, à capacidade de combinar os diferentes instrumentos tecnológicos, sejam eles simples ou complexos, para adequá-los às situações postas a partir da avaliação de suas potencialidades e limitações. Esta observação aponta que tal competência está em consonância com as discussões existentes no ensino de Matemática.

Na competência (6) notamos o destaque para a resolução de problemas diversos, incluindo aqueles que não estejam necessariamente atrelados com aspectos práticos. Para tal, aponta-se a capacidade de expressar respostas e sintetizar conclusões utilizando diferentes registros e linguagens. A partir de nossa análise, identificamos relações com duas características do letramento matemático, sendo elas matematizar, uma vez que ressalta a capacidade de transformar um problema que pode ser tanto do mundo real, como da própria matemática, e complementado pelo uso de linguagem simbólica, formal e técnica, e operações quando destaca a importância da compreensão e utilização dos constructos formais baseados em definições, regras e sistemas formais, bem como saber utilizar os algoritmos que explorem os conceitos envolvidos para a resolução de problemas.

Notamos nas competências (7) e (8) uma característica que, a nosso ver, se constitui como um desafio para Educação na atualidade, que é a formação de um aluno com perfil de pesquisador na Educação Básica. 
Ainda temos um modelo de ensino - em particular o ensino de Matemática - marcado por uma cultura instrumentalista, que ainda vê a Matemática como um conjunto de definições, conceitos e procedimentos de cálculo. Nesse sentido, vemos de forma positiva a indicação de desenvolver e discutir projetos a partir das demandas sociais, reconhecendo e valorizando a diversidade por meio de posicionamentos éticos e democráticos sempre interagindo com seus pares de forma cooperativa e trabalhando de forma coletiva na execução desses projetos, mas reconhecemos os limites existentes para a implementação dessa indicação. Essa orientação demanda características muitos presentes de comunicação e de raciocínio e argumentação.

A partir destas considerações, observamos que este conjunto de oito competências para o ensino de Matemática no Ensino Fundamental apresenta potencial para a formação de um aluno letrado em Matemática na perspectiva da OECD/PISA, quando prima por um indivíduo que seja capaz de identificar e atender o papel da Matemática no mundo, sabendo utilizá-la de forma que satisfaça as necessidades dos indivíduos.

\section{Considerações finais}

Revisitando nosso objetivo de analisar as características do Letramento Matemático contidas na BNCC do Ensino Fundamental e suas relações com a perspectiva de Letramento prevista pelo PISA, inferimos que as ideias e recomendações expostas por meio das oito competências gerais para o ensino de Matemática nesse segmento apresentam convergências com os conceitos de Letramento Matemático, o que, a nosso ver, é um apontamento de validação desse documento para sua implementação no ambiente escolar.

Dentre essas tendências, entretanto, observamos algumas que se apresentam como grandes desafios para o processo de ensino de Matemática na atualidade, quais sejam, a implementação e uso das que, conforme Machado, Ferreira e Marcelino (2019) ainda representam desafios para a escola de forma geral, seja pela condição infraestrutural, resultado de falta de investimento governamental, ou, em caso de haver condições, por medo de sair das suas zonas de conforto e enfrentar novas dinâmicas de sala de aula. Há de se considerar que a tecnologia hoje faz parte da 
vida e da forma de pensar das pessoas e desta forma impactam diretamente os processos de ensino e aprendizagem de Matemática.

Por meio das TICs novas formas de comunicação são estabelecidas e as relações humanas passam a ser mediadas também pelo computador com internet. É justamente a comunicação uma das tendências que observamos ter um papel de destaque na BNCC, uma vez que se observa uma preocupação na formação de um aluno que seja capaz de dialogar com seus pares na busca de resolução de problemas, tanto internos à Matemática, do cotidiano ou de outras áreas de conhecimento, como relativos à divulgação de resultados por meio de argumentos bem fundamentados.

Essas características oriundas da comunicação são fundamentais para a formação de alunos com espírito investigador, que foi outra orientação observada na BNCC. Entendemos que esta se constitui como um grande desafio para o processo educacional na atualidade, tendo em vista que ainda temos um processo de ensino fortemente marcado por um modelo que potencializa a passividade dos alunos em relação aos seus processos de aprendizagem.

Como destacamos em nossos procedimentos metodológicos para este estudo, priorizamos a análise da BNCC por meio de suas oito competências gerais para o ensino de Matemática no Ensino Fundamental. Sendo assim, finalizamos apontando a necessidade de aprofundamento dessas análises em estudos posteriores, que se desdobrem sobre as habilidades específicas das unidades temáticas e seus objetos de conhecimento.

Recebido em: 29/05/2020

Aprovado em: 25/08/2020

\section{Referências}

AGUIAR, G da S; ORTIGÃO, M. I. R. Letramento em Matemática: um estudo a partir dos dados do PISA 2003. BOLEMA: Boletim de Educação Matemática, Rio Claro, SP, v. 26, n. 42a, 2012, p. 1-22.

BARDIN, L. Análise de conteúdo. 1 $^{\text {a }}$ ed. São Paulo: Edições 70, 2016.

BORBA, M. de C; SCUCUGLIA, R. S.; GADANIDIS, G. Fases das tecnologias digitais em Educação Matemática: Sala de aula e internet 
em movimento. 1 ed. Belo Horizonte: Autêntica Editora, 2014 (Coleção Tendências em Educação Matemática).

BORBA, M de C; ALMEIDA, H. R. F. L; CHIARI. A.S.S. Tecnologias Digitais e a relação entre teoria e prática: Uma análise da produção em trinta anos de BOLEMA. BOLEMA: Boletim de Educação Matemática, Rio Claro, SP, v. 29, n. 53, 2015, p. 1115 - 1140.

BRASIL. Base Nacional Comum Curricular: Educação Infantil e Ensino Fundamental. Brasília: MEC/Secretaria de Educação Básica, 2017.

Parâmetros Curriculares Nacionais: introdução aos parâmetros curriculares nacionais. Brasília, DF: MEC/SEF, 1997.

LDB - Lei $n^{\circ}$ 9394/96, de 20 de dezembro de 1996. Estabelece as diretrizes e bases da Educação Nacional. Brasília: MEC, 1996.

CZIGEL. E; MONDINI. F; PAVANELO. E. A Base Nacional Comum Curricular (BNCC) e a organização da matemática no ensino fundamental. Revista Pesquisa Qualitativa. São Paulo/SP, v.7, n.15, 2019, p. 356-369.

D`AMBROSIO, U. Avaliação do alfabetismo matemático: intenções e possibilidades de pesquisa. In: FONSECA, M. Letramento no Brasil: Habilidades matemáticas. São Paulo: Global: Ação Educativa Assessoria, 2004, p. 31-46.

DAVID, M. Numeramento e escolarização. In: FONSECA, M. Letramento no Brasil: Habilidades matemáticas. São Paulo: Global: Ação Educativa Acessoria, 2004, p.65-90.

FONSECA, M. C. F. R. (Org.). Letramento no Brasil: habilidades matemáticas. São Paulo: Global, 2004.

GEE, J. Social linguistics and literacies: Ideology in discourses. New York: Routledge, 2015.

INAF. $2^{\circ}$ Indicador Nacional de Alfabetismo Funcional: um diagnóstico para a inclusão - primeiros resultados. São Paulo: Instituto Paulo Montenegro / Ação Educativa, 2002.

KLEIMAN, A. B. Os significados do letramento: uma nova perspectiva sobre a prática social da escrita. Campinas, SP: Mercado de Letras, 1995.

MACHADO, F.P; FERREIRA, R.S; MARCELINO, D.S. O uso das tecnologias digitais no ensino de matemática: Um olhar a partir da percepção 
dos alunos em uma escola do município de Breves - PA. In: I Congresso Amazônida Marajoara de Matemática, Breves/PA, 2019. Anais... Breves/PA, 2019.

MOREIRA, H.; CALEFFE, L. G. Metodologia da pesquisa para o professor pesquisador. 2. ed. Rio de Janeiro: Lamparina, 2008.

OECD. Pisa 2012. Assessment and Analytical Framework: Mathematics, Reading, Science, Problem Solving and Financial Literacy, OECD Publishing. Disponível em: http://dx.doi.org/10.1787/9789264190511en. Acesso em: 19 de fevereiro de 2020.

OLIVEIRA, Maria do Socorro. Gêneros textuais e letramento. Rev. Bras. Linguist. Apl. Belo Horizonte, v. 10, n. 2, p. 325-345, 2010. Disponível em: <http://www.scielo.br/scielo.php?script=sci_arttext\&pid=S198463982010000200003\&ng=en\&nrm=iso>. Acesso em: 06 de maio de 2020.

PERRENOUD, P. Construir competências desde a escola. trad. Bruno Charles Magne. Porto Alegre: Artmed, 1999.

PONTE, J. P. Práticas profissionais dos professores de Matemática. Portugal: Universidade de Évora, 2014.

ROSA, M; MUSSATO, S. Atividade-matemática-com-tecnologias-digitais e contextos culturais: Investigando o design como processo de cyberformação com professores de matemática. Jornal Internacional de Estudos em Educação Matemática, São Paulo, V.8(4), 2015.

SILVA. L.E. Educação Matemática e a Base Nacional Comum Curricular (BNCC): um desafio para a educação básica. Revista Humanidades e Inovação. V.6, n.6, 2019.

SOARES, M. Letramento: um tema em três gêneros. 3 ed. Belo Horizonte: Autêntica, 2009, 124 p.

Letramento: um tema em três gêneros. São Paulo: Autêntica 1999.

Letramento e escolarização. In: RIBEIRO. M (org.). Letramento no Brasil. São Paulo: Global, 2003, p.89-115.

TOLEDO, M. Alfabetismo, escolarização e educação matemática: Reflexões de uma professora de matemática. In: FONSECA, M. Letramento no Brasil: Habilidades matemáticas. São Paulo: Global: Ação Educativa Assessoria, 2004, p.92-107. 